\title{
Desenvolvimento do auto-conceito pela tutoria pedagógica por crianças do primeiro ciclo
}

\author{
Desenvolvimento do auto-conceito pela tutoria pedagógica
}

\author{
Fátima Simões \\ Leonor Rodrigues \\ Graça Esgalhado \\ Carina Guimarães
}

\begin{abstract}
Resumo
O conceito de identidade aparece, de forma recorrente, em diversas áreas da psicologia, embora nem sempre com o destaque que merece em termos do impacto que têm as relações interpessoais em grupos específicos. O seu carácter relacional e a sua tendência para o crescimento quando são proporcionadas experiências cooperativas, dão suporte à nossa investigação cujo objectivo era testar o impacto de um programa de intervenção junto de uma amostra de 60 crianças a frequentar o $1^{\circ}$ ciclo em escolas da Beira Interior. A adaptação portuguesa do Piers-Harris Children's Self-Concept Scale (Veiga, 1989) foi o instrumento utilizado numa metodologia de pré-teste/pós-teste com grupo de controlo. Os resultados apontam para uma evolução dos resultados do grupo experimental entre o pré-teste e o pós-teste.

Palavras-chave: Desenvolvimento do auto-conceito, Intervenção, Relações interpessoais.
\end{abstract}

\section{First grade self-concept improvement trough tutorial with their special needs classmates}

\begin{abstract}
Self-concept appears to be an important construct in most of psychology areas, although its impact on interpersonal relationships on specific groups wasn't always recognised. Its relational character and development tendency when cooperative experiences are promoted support our study which most important goal was to test an intervention program impact with 60 first grade students' participants. A pre-test/post-test research with experimental and control-group was performed with PiersHarris Children's Self-Concept Scale (Veigas' Portuguese adaptation, 1989). Results point out to experimental group self-concept improvement between pre-test and post-test.

Key words: Self-concept improvement, Intervention program, Interpersonal interaction.
\end{abstract}

\section{Desarrollo del auto concepto por la tutela pedagógica por niños del primer grado}

\section{Resumen}

El concepto de identidad aparece, de forma recurrente, en diferentes áreas de la psicología, pese a ni siempre tener el destaque que merece en términos del impacto que tienen las relaciones interpersonales en grupos específicos. Cuando son proporcionadas experiencias cooperativas, su carácter relacional y su tendencia para el crecimiento dan soporte a nuestra investigación, cuyo objetivo era testear el impacto de un programa de intervención junto a una muestra de 60 niños que frecuentaban el 1 o grado en escuelas de la Beira Interior. La adaptación portuguesa del Piers-Harris Children's Self-Concept Scale (Veiga, 1989) fue el instrumento utilizado en una metodología de pre-test/pos-test con un grupo de control. Los resultados apuntan para una evolución de los resultados del grupo experimental entre el pre-test y el pos-test.

Palabras clave: Desarrollo del auto concepto, Intervención, Relaciones interpersonales. 


\section{Introdução}

A relação dialógica que se estabelece entre o Eu e o Outro pressupõe que o Eu se conheça, identificando-se consigo próprio, diferenciando-se do outro, mas reconhecendo que este constitui uma identidade diferente, com outros valores, necessidades e capacidades; neste reconhecimento de identidades surgem os conceitos de respeito, empatia, exigência e partilha. A actividade da criança desenvolve-se no espaço e no tempo com a realidade material e com as pessoas com a actividade interpessoal consistindo na relação recíproca assimétrica e dialéctica entre pessoas, sujeitos capazes de sair de si mesmos e colocar-se no lugar do outro, sem deixar de serem eles próprios, sem manipular ou subalternizar o outro (Alarcão, 1991; Tavares, 1996).

$\mathrm{Na}$ actividade interpessoal está implícito o conceito de reciprocidade, sendo a acção projectada nos dois sentidos. Surge o sentimento profundo de relação de ajuda, o ajudar a ser, para que as pessoas se desenvolvam em todas as suas potencialidades. Em comparação com as pessoas mais novas, os adolescentes pensam em si próprios, em termos de características, sentimentos e emoções mais internas, facto que os leva a supor que têm muita coisa em comum com os outros, embora sejam diferentes (Alarcão, 1991; Damon \& Hart, 1982; Sprinthall \& Collins, 1994).

A noção de auto-conceito enquanto percursora da competência social, tem as suas raízes mais longínquas nos trabalhos de William James (James, 1890). Para este autor, o self, ou "eu psicológico», compreende todos os atributos que o indivíduo possa referir como fazendo parte de si próprio, desde o seu corpo, aptidões, até à suas posses, casa e família. Este self global subdivide-se em duas facetas diferenciados, uma em que o self é encarado como o conhecedor e tem uma função essencialmente executiva, é o autor do conhecimento, sendo designado por «l» $(\mathrm{Eu})$; o outro aspecto do self global é conhecido como o «Me» (Mim) e é representado por um agregado de coisas objectivamente conhecidas. Cada um destes aspectos não pode existir sem o outro, pois é impossível consciência sem conteúdo ou conteúdo sem consciência que permita tomar o seu conhecimento. James entendia não haver qualquer interesse para a compreensão do comportamento, no estudo do self enquanto autor do conhecimento, não o elegendo, portanto, como objecto de estudo da Psicologia, remetendo o seu estudo para o campo da Filosofia. Pelo contrário, o self enquanto objecto do conhecimento é encarado como muito importante para a explicação do comportamento humano, sendo de fundamental importância para a Psicologia a pesquisa sobre a sua natureza e dinâmica (Simões, 1997, 2001a).
Segundo James (1890) podem distinguir-se três áreas do self enquanto objecto: - self material, esta área do self reporta-se aos aspectos materiais com os quais a pessoa se identifica, para além do seu próprio corpo, integram esta zona do self todos os objectos e posses que o indivíduo possui; - self social, nesta classificação, o autor pretende captar a consciência que o indivíduo tem da forma como os outros o vêem, de acordo com os vários papeis que desempenha, uma pessoa tem vários selves sociais. Finalmente, a terceira área do self é o self espiritual, que corresponde ao reconhecimento individual de pensamentos e sentimentos privados, representando o que o indivíduo tem de subjectivo, é a área das emoções e dos desejos.

Outro autor do início do século que estudou o tema do auto-conceito foi Cooley (1902). A sua teoria centra-se, sobretudo, no processo de formação do self, tendo desenvolvido uma concepção do auto-conceito onde enfatiza a relação do eu com a sociedade. $O$ self tem vários aspectos, sendo o mais actuante o self social. Este self social, desenvolve-se, segundo o autor, a partir das observações que o sujeito faz da forma como as outras pessoas lhe respondem, ou seja, os indivíduos aprendem a definir-se a si próprios a partir da forma como os outros o definem, como se tratasse de uma imagem reflectida num espelho, é o processo de "looking glass", tal como foi designado pelo autor (Simões, 2001a). Este processo momentâneo desencadeia-se em três fases: o indivíduo percepciona a forma como deve aparecer frente às outras pessoas; o indivíduo interpreta a forma como os outros o avaliam e o indivíduo experimenta respostas afectivas ao julgamento percebido. $O$ interesse pelo estudo do autoconceito era evidente no início do século. Para além destes autores, outros desenvolveram estudos e teorizações sobre o tema, embora com o desenvolvimento e apogeu do behaviorismo radical as referências ao self e à mente tenham sido mais ou menos afastadas da terminologia e preocupações da Psicologia. Do ponto de vista behaviorista, o auto-conceito tem uma aura de misticismo, assemelhando-se, de alguma forma ao conceito de alma (Sherif, 1972). Em termos históricos verifica-se, assim, um lapso de tempo em que foram poucos os autores a debruçarem-se sobre este tema.

A importância do auto-conceito para a explicação do comportamento só é reafirmada durante a década de 50 , altura em que se verifica uma crescente influência na ciência psicológica das teorias humanistas e fenomenológicas. Rejeitando a visão determinista dos behavioristas, as correntes humanistas realçavam a importância da experiência pessoal e o que essa experiência poderia significar para 0 indivíduo. A tese principal era a de que o comportamento não é apenas influenciado pelas experiências passadas mas também 
pelos significados pessoais que cada pessoa atribui às suas percepções dessas experiências. De entre os vários autores destes correntes teóricas, Carl Rogers assumiu mesmo, como noção central da sua teoria, a noção do auto-conceito. Para Rogers (1951, citado por Sherif, 1972), - auto-conceito incluía todas as características do indivíduo de que ele tem consciência e sobre as quais ele crê exercer controle, sendo o self definido como um organizador, um padrão conceptual de percepções.

Paralelamente ao movimento humanista, as teorias cognitivistas iniciam também na década de 50 , uma contrareforma em relação ao behaviorismo radical e a noção de auto-conceito surge novamente com honras de primeiro plano. De entre os vários autores desta linha, destaca-se George Kelly e as suas formulações teóricas sobre a personalidade. Para Kelly (1955, citado por Sherif, 1972), o comportamento individual e a personalidade podem ser explicados em termos de um complexo de constructos e cognições que a pessoa possui e pelos quais se adapta ao mundo tal como este é percebido. Um constructo pessoal, segundo Kelly, é uma crença pessoal sobre o que dois objectos ou acontecimentos têm em comum e que os tornam diferentes de um terceiro, ou seja, os constructos definem-se a partir de um processo, a que o autor designa de comparações tríades. O sistema do Self estaria hierarquicamente organizado em constructos básicos, a partir dos quais uma pessoa mantém a identidade e existência, e constructos periféricos que podem ser alterados sem modificações sérias na estrutura de base (Bong \& Clark, 1999; Byrne \& Shavelson, 1986; Marsh, 1984).

O funcionamento do auto-conceito tem também sido apontado como uma teoria do Self, sendo o seu principal objectivo a optimização da balança dor/prazer do indivíduo ao longo da sua vida, sendo as outras duas funções básicas da teoria do Self a manutenção da auto-estima e a organização dos dados da experiência de modo a ser possível lidar com ela. Em termos de organização o autoconceito global ocupa um lugar de topo com as múltiplas facetas a serem distribuídas de forma hirárquica da mais geral para a mais específica (Shavelson \& Bolus, 1982; Shavelson, Hubner \& Staton, 1976). Por sua vez Markus e Wurf (1986) têm procurando clarificar a formação e o funcionamento do sistema de auto-conceito. Para este autores, o Self é uma estrutura dinâmica e interpretativa que medeia a maior parte dos processos interpessoais através do sistema de processamento de informação, regulação afectiva e processos motivacionais, bem como, um vasto conjunto de processos interpessoais, incluindo a percepção social, a comparação social e a interacção social (Markus \& Wurf, 1986). Com efeito, o auto-conceito tem sido apontado como uma variável de relevo em diversos contextos. Particularmente em contexto educativo, o seu carácter multidimensional confere-lhe um estatuto privilegiado pelo seu impacto, quer ao nível comportamental mais geral, quer ao nível dos resultados escolares, quer ainda ao nível da motivação para levar a cabo as tarefas (Bilimoria, Almeida \& Simões, 2007; Simões, 1997, 2001a, 2001b, 2002; Simões \& Ferrão, 2005; Simões, Franco \& Branco, 2002; Veiga, 2006).

Assim, a capacidade que acima referimos pode ser entendida como estruturante e auto-reguladora da assertividade e de aspectos sócioemocionais ligados ao comportamento intra e interpessoal, nomeadamente ao autoconceito. Este processo de regulação permitiria um melhor relacionamento com o meio social, com consequências para uma interacção dinâmica potenciadora de um ajustamento sócioemocional que seja consentâneo com os objectivos de formação pessoal e social (Simões \& Ferrão, 2005; Simões \& cols., 2002; Veiga, 2006).

Neste âmbito, autores como Markus e Wurf (1986), por exemplo, deram um contributo valioso ao apresentarem um modelo de auto-conceito dinâmico e actuante que funciona como regulador do processamento da informação nas relações interpessoais que mantém com o meio social. Podemos assim, entender que um bom desenvolvimento intra-individual ao nível do auto-conceito será benéfico para o relacionamento interpessoal, uma vez que enquanto mediador do processamento de informação presente no contexto cultural e social, o auto-conceito remete para uma percepção de si susceptível de influenciar o comportamento das situações específicas (Markus \& Kunda, 1986; Simões, 1997).

Assim, a escola deve proporcionar condições de desenvolvimento às crianças para que estas desenvolvam confiança em si, as suas capacidades individuais, competências intelectuais e sociais tal como postulado por diferentes reformas $e$, nomeadamente pela reforma curricular subordinada à Gestão Flexível do Currículo, (Despacho no 9590/99) e que exige que os alunos adquiram algumas competências de carácter social e ético, sendo o conceito assim definido pelo documento de trabalho emanado pelo Departamento de Ensino Básico: " 0 conjunto de conhecimentos e de capacidades de realização que aliado a características pessoais específicas, habilita 0 indivíduo a responder satisfatoriamente a uma dada situação, ou, mais brevemente, é um saber agir de acordo com as situações..." (Documento orientador/Departamento de Ensino Básico).

Ao nível do $1^{\circ}$ ciclo esta reforma pretendia que o aluno compreendesse, de forma progressiva, o processo de interacções entre o eu, o meio social e o meio natural, adquirindo noções básicas de uma educação para a cidadania - área a ser fomentada desde o $1^{\circ}$ ano do $1^{\circ}$ ciclo - que pretende implementar atitudes de participação, de reflexão, de cooperação e de espírito crítico. 
A introdução de crianças com Necessidades Educativas Especiais (NEE) no ensino regular tem colocado novos desafios pedagógicos aos professores. Para Shworles (1983), a revolução dos computadores e o uso genérico de tecnologias, tem tido um grande impacto na modificação que se operou na ciência nos últimos anos, tendo levado os responsáveis a repensar levou a repensar uma série de atitudes que suportam decisões $e$ determinam oportunidades e formas de vida. Na população com Necessidades Educativas Especiais verifica-se o contributo inestimável que as Novas Tecnologias da Informação têm vindo a dar à reabilitação e reeducação, quer na área do desenvolvimento cognitivo e psicomotor, quer ainda como meio alternativo ou aumentativo de comunicação e de facilitação da realização de uma determinada tarefa, permitindo reforçar o desenvolvimento pessoal e social destas crianças e dos seus pares. As Novas Tecnologias da Informação são um recurso reabilitativo, por vezes o único, numa população com severas disfunções motoras, pela possibilidade que promovem no acesso ao desenvolvimento, à escola e ao trabalho. Estes sistemas foram concebidos com o objectivo de possibilitar a comunicação e conceptualização das pessoas impossibilitadas de comunicar oralmente e darIhes a possibilidade de participarem na vida social. Dos vários sistemas alternativos de comunicação o Vocabulário MAKATON, é um dos que funciona como meio alternativo ou aumentativo da comunicação, numa perspectiva evolutiva ou de desenvolvimento, tendo como padrão o processo normal de aquisição de linguagem.

Com a presente investigação pretende-se verificar qual o impacto de um programa de promoção de competências sociais, no desenvolvimento do auto-conceito através da utilização da tutoria pedagógica por parte de crianças do primeiro ciclo junto dos seus pares que apresentam Necessidades Educativas Especiais. Tentar-se-á responder às seguintes questões: será que (1) a utilização de Tecnologias de Informação e de Comunicação (TIC) com uma criança com problemas graves de comunicação ajuda a promover o auto-conceito junto dos seus pares escolares?; e (2) a utilização, por parte dos alunos, de estratégias de trabalho cooperativo, de tutoria pedagógica entre pares e de auto-reflexão são promotoras do desenvolvimento do seu auto-conceito?

\section{Método}

\section{Participantes}

Para o desenvolvimento deste estudo foi constituída uma amostra por conveniência (Almeida \& Freire, 2007) para a qual foram envolvidos 60 alunos do $2^{\circ}$ ano de escolaridade de escolas do $1^{\circ}$ Ciclo do Ensino Básico do concelho do Fundão (Portugal), cujas idades oscilavam entre os 7 e os 8 anos $(M=7,2 ; D P=0,32)$, sendo 31 do sexo feminino e 29 do sexo masculino. Depois de obtidas as autorizações dos pais e/ou encarregados de educação e garantido o carácter voluntário e confidencial da sua participação, os alunos acederam ao pedido de colaboração por parte das investigadoras.

O grupo experimental ficou constituído pelos alunos das turmas $A$ do $2^{\circ}$ ano do $1^{\circ}$ ciclo de duas escolas do Ensino Básico e o grupo de controlo pelos alunos das turmas B das mesmas escolas. Em ambos os grupos de participantes existia uma criança com multideficiência. No entanto, apenas no grupo experimental os participantes tiveram um papel activo junto da criança com Necessidades Educativas Especiais.

\section{Instrumentos e Materiais}

Tendo como objectivo a avaliação do auto-conceito foram utilizados dois tipos de instrumentos: Escala de Autoconceito Piers-Harris Children's Self-Concept Scale (PHCSCS) adaptada para a população portuguesa por Veiga (1989) e aqui utilizada em em dois momentos (timing): pré-teste e pós-teste. Esta escala é constituída por seis factores: Factor I- Aspecto comportamental (AC); Factor II- Ansiedade (NA); Factor III- Estatuto intelectual e escolar (EI); Factor IV- Popularidade (PO); Factor VAparência e atributos físicos (AF) e Factor VI- Satisfaçãofelicidade (SF). Para além desta escala foi também utilizado o Teste das Matrizes Progressivas Coloridas de Raven (M. P. C. R.), aferidas para a população portuguesa por Simões (1995); esta escala foi igualmente aplicada em dois momentos (timing): pré-teste e pós-teste.

Por seu turno, durante a fase de intervenção foi utilizado o Vocabulário MAKATON. Este software foi criado para resolver graves problemas de comunicação e de linguagem em crianças ou adultos com multideficiência, deficiência mental ou motora, através de um vocabulário básico que seja expressão das suas necessidades imediatas. Trata-se de um programa alternativo ou aumentativo da comunicação, que utiliza técnicas estruturadas de ensino e o auxílio de um qualquer meio de comunicação - gestual, simbólico ou em combinação - a acompanhar a fala, no ensino do vocabulário. Este programa foi concebido por Margaret Walker inicialmente para adultos deficientes mentais, alguns deles surdos, residentes numa instituição hospitalar britânica, tendo sido, posteriormente, adaptado a outros níveis etários como crianças e adolescentes (Tetzechner \& Martinsen, 2000; Walker, 1990). A sua expansão por diversos países, entre os quais Portugal, implicou não só a sua adaptação em termos culturais e linguísticos, mas ainda ao nível da utilização da língua gestual própria da comunidade de surdos desses países, cujos itens lexicais se incluíssem no Vocabulário. 
Este programa tem como objectivos facilitar, desencadear ou desenvolver a linguagem, de acordo com os seguintes parâmetros: minimizar a complexidade do processo linguístico, aos níveis da expressão e da compreensão; clarificar o significado do que é expresso, pela utilização de quaisquer meios disponíveis; e limitar o número de vocábulos de uma língua a um conjunto reduzido, segundo critérios de prioridades relacionadas com a sua frequência de ocorrência e a satisfação das necessidades básicas fundamentais. Deste modo, o Vocabulário MAKATON é constituído por cerca de três centenas e meia de palavras ou expressões, subdivididas em oito níveis e ordenadas segundo o grau de complexidade dos conceitos e estruturas linguísticas a partir dos quais podem ser gerados.

$\mathrm{Na}$ selecção dos conceitos e sua ordenação, parte-se do nível básico e essencial, tomando-se como referência o processo normal de aquisição de linguagem (sequência e etapas de desenvolvimento), seguindo, progressivamente para níveis que implicam maior abstracção. Trata-se de promover uma evolução do mais simples para o mais complexo (vocábulos correspondentes a conceitos definidos como unidades e posteriormente combinados em frases), aplicação a casos e ambientes diversos, sendo necessário o ajustamento do vocabulário à situação específica de cada indivíduo; o programa funciona como padrão permitindo a avaliação da linguagem da criança, determinando o essencial e o acessório, revelando as lacunas que dificultam a evolução do processo de aquisição da linguagem. O professor poderá, assim, ajustar a sua forma de expressão de modo a tornar a sua mensagem compreensível (adequando e simplificando o vocabulário); a promoção da utilização funcional da aprendizagem é parte integrante deste programa.

Quanto à sua natureza, os meios alternativos de comunicação podem dividir-se em gráficos e gestuais (características comuns da modalidade visual); o seu uso tem que atender, no entanto, às capacidades individuais. No Vocabulário MAKATON podem-se utilizar os gestos ou símbolos, ou ainda uma combinação de ambos, a complementar simultaneamente a fala. Os símbolos são muito icónicos, de fácil leitura e memorização, de pouca exigência gráfica, podendo ser utilizado qualquer sistema de símbolos, desde que cubra o vocabulário do programa. As vantagens do uso dos símbolos gráficos, para além das já referidas, são as que se prendem com as limitações motoras que impedem a utilização da linguagem gestual. Os gestos foram seleccionados em função do seu grau de iconicidade e simplicidade em termos de percepção e de articulação (produção).

As vantagens do uso dos gestos na comunicação destas crianças, podem subdividir-se em dois grupos: relativas aos aspectos de natureza perceptiva; e relativas aos aspectos da produção. Nestas últimas encontram-se as vantagens relacionadas com o controlo motor, uma vez que é mais fácil fazer um gesto do que articular uma palavra, pois esta implica controlo motor mais fino e complexo e torna-se possível manejar o braço ou a mão da criança ajudando-a a fazer o gesto, o que não acontece em relação à pronúncia de palavras; nas primeiras as vantagens têm a ver com as características icónicas dos gestos que facilitam a sua relação com o referente, com a possibilidade de simultaneamente se apresentar o gesto e o referente, sendo a sua percepção processada na mesma modalidade (visual), com a duração do gesto a poder ser ampliada sem alterar a sua forma, prolongando-se no tempo a permanência do estímulo visual.

Outros mecanismos da língua gestual estão associados à iconicidade de modo a clarificar o significado expresso, como, por exemplo a localização (pela ocupação dum lugar determinado no espaço gestual), o movimento (implícito ou não) e a direccionalidade (associados ao movimento através da indicação por exemplo do ponto de origem), sendo o objectivo final deste programa a aquisição e utilização da linguagem oral como meio de comunicação. Assim, este programa permite uma evolução significativa no desenvolvimento linguístico, uma optimização das capacidades de atenção, de estabelecer e manter o contacto visual, bem como uma melhor adequação dos comportamentos às diversas situações ao nível da socialização e da interacção comunicativa, necessário descer ao nível de cada aluno de modo a despertar e a activar todas as suas capacidades para promover a comunicação.

\section{Procedimento}

Os instrumentos foram aplicados durante o período lectivo, com autorizações prévias da Direcção Regional de Educação e do professor titular de turma. Tendo em conta a especificidade das faixas etárias dos alunos, todas as instruções foram lidas em voz alta e amplamente explicadas. Este procedimento teve por objectivo reduzir possíveis enviesamentos provocados por um nível ainda reduzido de compreensão, quer escrita, quer oral, por parte das crianças a frequentarem $0 \quad 2^{\circ}$ ano de escolaridade. Tratou-se de um estudo com grupos naturais de conveniência e, por isso, com selecção amostral de carácter não aleatório. Assim, e sendo um estudo de design pré-teste/pós-teste com grupo de controlo, os mesmos instrumentos de avaliação psicológica foram aplicados antes e depois do programa de intervenção. $\mathrm{Na}$ fase prévia à intervenção foram realizadas diversas acções de formação de docentes que visavam assegurar formação em estratégias de trabalho cooperativo e de metodologias activas diversificadas.

$\mathrm{Na}$ fase de intervenção, no grupo experimental, foi implementado um programa de intervenção para desenvolvimento do auto-conceito através de uma 
dinâmica de metodologias activas e interactivas. Assim, adoptando uma pedagogia diferenciada, que considera a diversidade e a originalidade própria de cada um, independentemente das suas características físicas, sociais ou cognitivas tentou-se contribuir para a igualdade de oportunidades. O programa de intervenção foi organizado para ser aplicado no contexto da sala de aula, e norteado por uma filosofia de escola inclusiva tendo como meta uma educação para as relações interpessoais e para a cooperação, com vista ao desenvolvimento de um auto-conceito positivo. Antes do início das sessões foi passado aos grupos experimental e de controlo, um teste de capacidade intelectual, variável a controlar através do estudo da covariância, no sentido de colocar todos os sujeitos em igualdade de circunstâncias relativamente a esta variável: a versão portuguesa do Teste das Matrizes Progressivas Coloridas de Raven (M. P. C. R.). No que concerne à avaliação do auto-conceito utilizou-se a Escala de Auto-conceito Piers-Harris Children's Self-Concept Scale (PHCSCS) adaptada para a população portuguesa por Veiga (1988). No final da intervenção adoptou-se o mesmo procedimento.

A intervenção delineada a partir dos pressupostos teóricos apresentados na introdução deste artigo, foi desenvolvida ao longo de dois eixos, num total de vinte e cinco sessões, com uma periodicidade bi-semanal, que decorreram entre Dezembro de 2000 e Junho de 2001, contemplando conteúdos curriculares (Estudo do Meio, à Língua Portuguesa e à Matemática) e não curriculares (Competências de Comunicação e de Relacionamento Interpessoal e de Grupo e Educação para a Cidadania). Os dois exos a que acima se faz referência são: (1) actividades de comunicação não verbal, treino assertivo e resolução de problemas em grupos; e (2) Aplicação de estratégias de metodologias activas que incluíram aprendizagem a pares, tutoria pedagógica e aprendizagem cooperativa privilegiando a monitorização, por parte das crianças do grupo experiemntal, de algumas actividades da criança multideficiente. Para este fim recorreu-se à utilização das Tecnologias de Informação e Comunicação, de acordo com o descrito na rubrica Instrumentos $e$ Materiais.

\section{Resultados}

No que se refere aos resultados, como pode verificarse no Tabela 1 encontram-se as médias e desvios-padrão obtidos para as diferentes dimensões do auto-conceito. A dimensão Aspecto comportamental (AC) faz referência à percepção que o sujeito tem do seu comportamento em várias situações e da responsabilidade que tem pelas suas acções, quer em casa, quer na escola. Da análise da Tabela 1 pode-se constatar que o grupo experimental revelou, entre o pré-teste e o pós-teste uma descida dos valores médios do aspecto comportamental com uma descida insignificante (de 13,6 para 13,5), contemplando uma variabilidade muito acentuada entre os indivíduos (de 1,73 para 2,62 ). No grupo de controlo, a mesma medida subiu (de 12,9 para 13,8) com uma grande variabilidade (de 3,20 para 1,44).

Em seguida procedeu-se a uma análise de variância de medidas repetidas. Da análise dos efeitos inter-individuais Timing (pré-teste e pós-teste) e Grupo*Timing) pode concluir-se que os mesmos não são significativos. Tais resultados referem-se aos factores que distinguem os indivíduos entre si, bem como da interacção entre timing e a pertença a um dos grupos (experimental ou controlo). A nível intra-individual verifica-se um efeito estatisticamente significativo $[F(1,60)=279,335 ; p<0,001]$.

A dimensão Ansiedade (AN) refere-se à insegurança, preocupações, inquietações e medos com que a pessoa se encara a si própria e às situações, encontrando-se, por isso ligada a emoções e expectativas negativas. Da análise da Tabela 1 constata-se que o grupo experimental revelou, entre o pré-teste e o pós-teste uma descida dos valores médios da ansiedade com uma descida (de 9,6 para 8,9), assumindo uma variabilidade pouco acentuada entre indivíduos (de 3,03 para 2,88). No grupo de controlo, a mesma medida subiu (de 9,0 para 9,9) com uma escassa variabilidade (de 2,74 para 2,36).

Em seguida procedeu-se a uma análise de variância de medidas repetidas .Da análise dos efeitos inter-individuais Timing (pré-teste e pós-teste) e Grupo*Timing) podemos concluir que os mesmos são estatisticamente significativos para $[F(1,60)=55,600 ; p<0,05]$. Tais resultados referemse aos factores que distinguem os indivíduos entre si, bem como da interacção entre timing e a pertença a um dos grupos (experimental ou controlo). A nível intra-individual verifica-se um efeito estatisticamente muito significativo para $[F(1,60)=64,600 ; p<0,001]$. A partir da análise da Figura 1 (médias estimadas) podemos verificar a evolução dos índices de ansiedade. No seu conjunto, estes dados permitem inferir que, no grupo experimental, houve um decréscimo dos níveis de ansiedade. Pelo contrário, o grupo de controlo apresenta uma tendência crescente no mesmo facto. 
Tabela 1. Média e desvio-padrão para as Dimensões do Auto-Conceito

\begin{tabular}{|c|c|c|c|c|c|c|c|c|}
\hline \multirow{2}{*}{ Grupo } & \multirow{2}{*}{ Timing } & & \multicolumn{6}{|c|}{ Dimensões do auto-conceito } \\
\hline & & & $\mathrm{AC}$ & NA & EI & $\mathrm{PO}$ & $\mathrm{AF}$ & SF \\
\hline \multirow{4}{*}{$\begin{array}{l}\text { Experimental } \\
(N=30)\end{array}$} & Pré-teste & $M$ & 13,6 & 9,6 & 11,1 & 7,8 & 6,0 & 5,4 \\
\hline & & $D P$ & 1,73 & 3,03 & 2,22 & 1,72 & 0,89 & 1,24 \\
\hline & Pós-teste & $M$ & 13,5 & 8,9 & 11,1 & 8,2 & 6,0 & 6,0 \\
\hline & & $D P$ & 2,62 & 2,88 & 2,75 & 2,51 & 0,85 & 1,43 \\
\hline \multirow{4}{*}{$\begin{array}{l}\text { Controlo } \\
(N=30)\end{array}$} & Pré-teste & $M$ & 12,9 & 9,0 & 10,1 & 7,8 & 5,3 & 5,3 \\
\hline & & $D P$ & 3,20 & 2,74 & 2,84 & 1,21 & 0,83 & 1,47 \\
\hline & Pós-teste & $M$ & 13,8 & 9,9 & 9,0 & 8,2 & 5,4 & 6,0 \\
\hline & & $D P$ & 1,44 & 2,36 & 4,05 & 1,56 & 1,23 & 1,26 \\
\hline
\end{tabular}

Legenda: AC - Aspecto Comportamental; AN - Ansiedade; EI - Estatuto intelectual e Escolar;

PO - Popularidade; AF - Aparência e atributos Físicos; SF - Satisfação/Felicidade

Evolução pré-teste/pós-teste

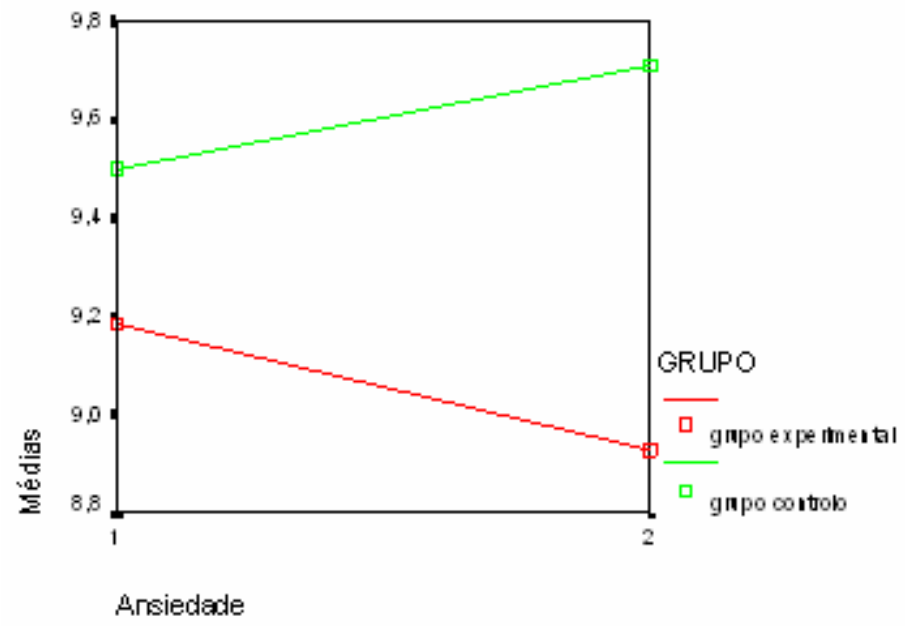

Figura 1. Médias estimadas ára a dimensão Ansiedade para os grupos experimental e controlo

A dimensão Estatuto intelectual e escolar refere-se à forma como um indivíduo se vê a si próprio relativamente ao sucesso que obtém nas tarefas intelectuais, tendo a ver com o que supõe ser a admiração que os seus pares the dispensam fruto das suas capacidade de aprendizagem. Da análise da Tabela 1 constata-se que, entre o pré-teste e o pós-teste, o grupo experimental não revelou qualquer aumento dos valores médios $(11,1)$ na medida de pósteste, embora o desvio-padrão seja um pouco mais elevado $(2,22 ; 2,75)$. No grupo de controlo os valores da média desceram (de 10,1 para 9,0) e apresentam uma variabilidade muito elevada no pós-teste $(4,05)$. Para testar a significância das diferenças entre os valores médios procedemos a uma análise de variância de medidas repetidas dos resultados referentes à diferenciação inter- individual. Esta análise não encontrou efeitos estatisticamente significativos. No que se refere aos resultados a nível intra-individual verifica-se um efeito estatisticamente significativo $[F(1,60)=164,921$; $p<0,001$ ] para a interacção.

A forma como um indivíduo se percebe relativamente às relações que estabelece com os seus pares, à facilidade com que faz amizades, ao grau de popularidade e ao modo como se sente incluído ou desejado, reflecte a dimensão Popularidade. Os resultados descrevem um aumento dos valores do factor popularidade entre o préteste e o pós-teste, quer no grupo experimental (de 7,8 para 8,20), quer no grupo de controlo (de 1,21 para 1,56 ). Observando a variabilidade entre os sujeitos verifica-se que o nível de popularidade em ambos os grupos subiu, 
não apresentando, no entanto, diferenças estatisticamente significativas. Os dados da análise intra-individual revelam diferenças estatisticamente muito significativas para $[F(1,60)=140,263 ; p<0,001]$.

No que se refere à dimensão Aparência e atributos físicos constata-se que, o grupo experimental obteve, entre pré-teste e pós-teste, uma subida dos valores médios referentes ao que os indivíduos pensam sobre a sua aparência e atributos físicos, (de 5,6 para 5,9), não apresentando variabilidade significativa, quer no primeiro momento, quer no segundo $(0,89 ; 0,85)$. Embora verifiquemos que o grupo de controlo também obteve uma subida, a variabilidade dos resultados é muito maior (de 0,83 para 1,23 ). Para testar a significância das diferenças entre os valores médios procedeu-se a uma análise de variância de medidas repetidas dos resultados tendo concluído que tais diferenças não são estatisticamente significativas. Dos resultados da análise intra-individual verificamos uma diferença estatisticamente muito significativa para $[F(1,60)=292,687 ; p<0,001]$.

Os resultados descritivos da dimensão Satisfaçãofelicidade indicam que, no grupo experimental os valores médios sofreram uma diminuição (de 5,4 para 6,0 ) entre 0 pré-teste e o pós-teste, mas com uma variabilidade acentuada (de 1,24 para 1,43). Contudo no grupo de controlo verifica-se também uma evolução crescente dos valores médios do mesmo factor (de 5,3 para 6,0) com uma variabilidade muitíssimo acentuada, sobretudo no préteste $(1,47 ; 1,26)$. Do teste da significância das diferenças entre os valores médios de cada grupo conclui-se não serem os mesmos estatisticamente significativos, embora ao nível intra-individual as diferenças tenham apresentado valores estatisticamente muito significativas para $[F(1,60)=1755,313 ; p<0,001]$

\section{Discussão dos Resultados}

Partindo do pressuposto de que a escola tem responsabilidades no desenvolvimento pessoal dos alunos, nomeadamente no que toca à sua identidade, a diversidade intelectual e cultural pode ser encarada como factor de enriquecimento para cada um, caso proporcione o desenvolvimento de competências pessoais promotoras de sucesso nos desempenhos, quer académicos, quer sociais e/ou emocionais (Almeida, 2002; Rosário, Soares, Nuñes, González-Pienda \& Simões, 2004).

Uma reflexão baseada na interpretação dos resultados do nosso estudo permite-nos afirmar, com alguma segurança, que a intervenção foi eficaz. Corroborando a afirmação atrás proferida temos que, a nível intra-individual os resultados para os factores Aspecto comportamental; Ansiedade; Popularidade; Estatuto intelectual e escolar; e Aparência e Atributos Físicos são significativos $(p<0,001)$ para os efeitos da interacção entre variáveis. As médias marginais estimadas indicam uma evolução decrescente no factor Ansiedade e uma evolução crescente nos factores Popularidade e Aparência e Atributos Físicos. Infere-se que a aprendizagem cooperativa dotou os participantes de um conjunto de competências que proporcionaram o seu desenvolvimento, atitudes positivas e um equilíbrio psicológico mais ajustado (Simões, 2001a; Simões, 2001b; Simões \& cols., 2002). As relações interpessoais que se estabelecem entre os pares e com os professores ou educadores são fundamentais, tanto para o processo de formação do auto-conceito, como para a aquisição de comportamentos sociais considerados ajustados. Ao nível interindividual os valores não são significativos para nenhum dos factores.

Com efeito, retomando as duas questões de investigação, verificamos que através do uso das Tecnologias de Informação e de Comunicação (TIC) com uma criança com problemas graves de comunicação a par de uma utilização, por parte dos alunos, de estratégias de trabalho cooperativo, de tutoria pedagógica entre pares e de auto-reflexão apontam para uma tendência de crescimento no desenvolvimento do auto-conceito dos participantes do grupo experimental pares. Estes resultados vão no sentido de um desenvolvimento das actividades da criança num quadro espacio-temporal de uma realidade interpessoal que se materializa na relação recíproca assimétrica e dialéctica entre sujeitos que se tornam capazes de colocar-se no lugar do outro, sem deixar de serem eles próprios, sem manipular ou subalternizar o outro (Alarcão, 1991; Tavares, 1996).

Esta tendência de crescimento, num tempo de intervenção reduzida produziu efeitos positivos em cada um dos indivíduos, embora não tenha sido suficientemente longa e consistente para revelar alterações que fossem significativamente diferenciadoras em termos de grupo. É nossa convicção que, com programas mais sistemáticos e de longa duração, os efeitos tendenciais revelados pelos resultados patentes nas médias estimadas poderão vir a revelar-se diferenciadoras entre grupos, sustentando assim a necessidade de promover a inclusão de intervenções desta natureza.

De todos os resultados positivos verificados, destacase a descida dos níveis de ansiedade que é estatisticamente significativa para os efeitos inter e intraindividuais para o grupo experimental. Estes resultados corroboram os de outras investigações (Simões, 2001b; Simões \& cols., 2002) e alertam também para o facto de tendência de subida dos níveis de ansiedade no grupo de controlo, de acordo com a magnitude das médias estimadas, poder significar a possibilidade de um aumento dos níveis de ansiedade à medida que as crianças vão avançando no $1^{\underline{0}}$ ciclo do Ensino Básico, sobretudo 
quando não são tomadas medidas controladas para promover a auto-estima.

Neste contexto, e retomando as perspectivas sobre $o$ Self enquanto estrutura dinâmica e interpretativa que estabelece uma mediação dos processos interpessoais através do sistema de processamento de informação, assegurando a regulação afectiva e dos processos motivacionais, bem como, um vasto conjunto de processos interpessoais, incluindo a percepção social, a comparação social e a interacção social (Markus \& Wurf, 1986) podemos concluir que a aprendizagem cooperativa aqui proporcionada permitiu a implementação de competências sociais, pessoais e académicas, que conduziram ao desenvolvimento do pensamento crítico, a atitudes positivas e um melhor equilíbrio psicológico e conduzem a um melhor auto-conceito, que tem sido indicado (Bilimoria \& cols., 2007; Simões, 1997, 2001a, 2001b, 2002; Simões \& cols., 2002; Simões \& Ferrão, 2005; Veiga, 2006) como uma das variáveis com maior impacto motivacional em contexto educativo.

Existiria então uma relação privilegiada entre a motivação e a percepção de si, começando a escola a estar mais consciente da importância de redefinir objectivos e estratégias que permitam melhorar a competência social e as relações interpessoais dos seus alunos, tendo como finalidade o desenvolvimento global do aluno, incluindo objectivos académicos e afectivoemocionais (Almeida, Guisande, Bilimoria \& Simões, 2006; Rosário \& cols., 2005). Em futuros estudos importará desenvolver programas mais longos, eventualmente longitudinais e averiguar os factores que mais poderão contribuir o desenvolvimento do auto-conceito e, pela sua via, um aumento da motivação e do bem-estar psicológico.

\section{Referências}

Alarcão, I. (1991). Dimensões de Formação. Em I. Alarcão \& J. Tavares (Eds). Formação Contínua: Realidades e Perspectivas (pp. 69-77). Aveiro: Universidade de Aveiro.

Almeida, L. S. (2002). Facilitar a aprendizagem: Ajudar os alunos a aprender e a pensar. Psicologia Escolar e Educacional, 6(2), 155-165.

Almeida, L. S., \& Freire, T. (2007). Metodologia da Investigação em Psicologia e Educação. Braga: Psiquilíbrios Edições.

Almeida, L. S., Guisande, A., Bilimoria, H., \& Simões, F. (2006). Os métodos de estudo e as dimensões do auto-conceito: Análise da sua relação em adolescentes. Psicologia e Educação, 5(2), 5163.

Bilimoria, H., Almeida, L. S., \& Simões, F. (2007). Auto-conceito, auto-regulação da aprendizagem e rendimento escolar. Psicologia e Educação, 6(2), 45-59.
Bong, M., \& Clark, R. E. (1999). Comparison between self-concept and self-efficacy in academic motivation research. Educational Psychologist, 34(3), 139-153.

Byrne, B. M., \& Shavelson, R. J. (1986). On the structure of adolescent self-concept. Journal of Educational Psychology, 78(6), 474-481.

Cooley, C. H. (1902). Human nature and social order. New York: Scribner's.

Damon, N., \& Hart, D. (1982). The Development of Self. Under standing from infancy through adolescence. Child Development, 53, 841-864.

James, W. (1890). Principles of Psychology. New York: Henry Holt.

Markus, H., \& Wurf, E. (1986). The dynamic self-concept: A social Psychological perspective. Annual Review of Psychology, 51(4), 858-856.

Marsh, H. (1984). Self-concept, social comparison and ability grouping: A reply to Kulik and Kulik. American Educational Research Journal, 21(4), 165-181.

Rosário, P. Soares, S., Nuñes, C., González-Pienda, J., \& Simões, F. (2004). Ansiedade face aos testes e auto-regulação da aprendizagem: Variáveis emocionais do aprender. Psicologia e Educação, 3(1), 15-26.

Rosário, P., Soares, S., Morão, R., Nuñez, C., González-Pienda, J., Simões, F., \& Pina, F. (2005). Disrupção percebida e autoregulação da aprendizagem no Ensino Básico. Psicologia e Educação, 4(1), 77-90.

Shavelson, R. J., \& Bolus, R. (1982). Self-concept: The interplay of theory and methods. Journal of Educational Psychology, 74(1), 317.

Shavelson, R. J., Hubner, J. J., \& Staton, J. C. (1976). Selfconcept: Validation of construct interpretations.Review of Educational Research, 46, 407-441.

Sherif, M. (1972). International Encyclopedia of Social Sciences, 14, 150-158.

Simões, F. (1997). Auto-conceito e formação pessoal em contexto escolar. Revista Portuguesa de Pedagogia, Ano XXXI (1, 2 e 3), $195-210$.

Simões, F. (2001a). Relações interpessoais: Perspectivas e fundamentos. Brotéria, 152(2), 147-157.

Simões, F. (2001b). O interesse do auto-conceito em Educação. Lisboa: Plátano.

Simões, F., Franco, C., \& Branco, M. L. (2002a). Papel da resolução de conflitos e auto-regulação socioemocional, Inovação, 15(1,2,3), 131-148.

Simões, F. (2002). Comunidade educativa e conquista da identidade. Em M. F. Patrício (Org), Globalização e Diversidade. A Escola Cultural: uma resposta. Porto: Porto Editora.

Simões, F., \& Ferrão, M. E. (2005). Competência percebida e desempenho escolar em Matemática. Estudos em Avaliação Educacional, 16(32), 25-41. 
Simões, M. F., Franco, C. \& Branco, M. L. (2002). Papel da Resolução de Conflitos e auto-regulação socioemocional, Inovação, 15 (1,2,3), 131-148.

Sprinthall, N. A., \& Collins, W. A. (1994). Psicologia do Adolescente. Lisboa: Fundação Calouste Gulbenkian.

Tavares, J. (1996). Uma sociedade que aprende e se desenvolve. Relações Interpessoais. Porto: Porto Editora.

Tetzchner, S., \& Martinsen, H. (2000). Introdução à comunicação aumentativa e alternativa. Porto: Porto Editora.
Veiga, F. H. (1989). Escala de autoconceito: Adaptação portuguesa do Piers-Harris Children's Self-Concept Scale. Psicologia, 7(3), 275-284.

Veiga, F. H. (2006). Uma nova versão da escala de autoconceito Piers-Harris Children's

Self-Concept Scale (PHCHCS-2). Psicologia e Educação, 5(1), 3947.

Walker, M. (1990). El lenguaje Makaton. Usos britanicos y internacionales (p. 248-258). Em Actas XVI Congreso Nacional de AELFA, 1990, INSERSO, Salamanca, ISBN 84-86852-92-7.

Recebido em: 19/05/2008

Revisado em: 17/11/2008

Aprovado em: 17/12/2008

\section{Sobre as autoras}

Fátima Simões (fsimoes@ubi.pt) Professora Associada do Departamento de Psicologia e Educação - Universidade da Beira Interior (Covilhã, Portugal)

Leonor Rodrigues (leo_rodrigues11@hotmail.com) Professora especializada em educaçao especial na Unidade de Apoio à Educação de Alunos Multideficientes do Fundão

Graça Esgalhado (mgpe@ubi.pt) Professora Auxiliar do Departamento de Psicologia e Educação - Universidade da Beira Interior (Covilhã, Portugal)

Carina Guimarães (scmg@ubi.pt) Assistente do Departamento de Psicologia e Educação - Universidade da Beira Interior (Covilhã, Portugal) 